Vol. 3, No. 3, September 2021, pp. 352-361,doi.org:10.52567/pjsr.v3i3.257

www.pjsr.com.pk

\title{
A PHENOMENOLOGICAL EXPLORATION OF VIRTUAL LEARNERS' EXPERIENCES
}

\author{
Raheel Farooqui \\ Senior Lecturer, Bahria University Karachi Campus, Pakistan \\ raheelf82@gmail.com \\ Sehrish Qasim Ali \\ Senior Lecturer, Bahria University Karachi Campus, Pakistan \\ sehrishqasim95@gmail.com \\ Mehdi Abbas \\ Senior Lecturer, Bahria University Karachi Campus, Pakistan \\ mehdiabbas85@gmail.com
}

\begin{abstract}
This study explores and observe the experiences and believes of students regarding online education system. The study was conducted online in Karachi, Sindh, Pakistan. The phenomenological technique of the study tried to incorporate patron notion via manner of online education through different systems in education industry as to fascinate maximum students, and additionally to satisfy the educational needs of students by taking online classes. This study is qualitative in nature, primary and secondary source of codes are selected, examined and interpreted. The data collected by using structured interviews (Close ended questionnaire) has been supported by relevant secondary literature that further supported to conduct qualitative research based on phenomenology. The online education in Pakistan Karachi has great importance, it's a growing phenomenon, but facing hurdles of time comments from trainer; isolation, lack of self-law, unapproachable technical useful resource from trainers, and lack of selfmotivation among students. This study gets beneath the parameters of educational credential to provide a motive behind the comprehensive functionality of the online education system.
\end{abstract}

Keywords: Students, Perception, Online education, Qualitative, Online Classes, Virtual.

\section{INTRODUCTION}

The expansion of online learning within the previous decade has been significantly increased. Similarly, there were limited students who registered to virtual learning in 1998; However, Allen \& Seaman (2010) studied 2500 universities revealing that approximately 5.6 million students in 2009 were taking virtual learning courses. Approximately $30 \%$ of students were part of a virtual learning courses. Another research found similar results of $21 \%$ enrollment growth, despite the fact that overall virtual learning growth in higher education was only $2 \%$. Moreover, the $21 \%$ growth rate for online enrollments exceeds the less than $2 \%$ growth of the overall higher education student population. Above statistics specified that virtual knowledge has turn out to be a significant style of delivering teaching in higher education. Moreover, Bianco \& Carr-Chellman, 2002 studied that innovative futuristic technologies have far more benefits than the traditional schooling system. Technologies including virtual group meetings, internet, streaming videos, etc. have more operational benefits such as wide range of learning capacity, more capability of accessing the education as well as inexpensive for several students. Another benefit of new technologies is providing the opportunity to many students to get the higher education. Thus, virtual learning, prominently increasing its own importance amongst institutions and students. Consequently, Office of Sustainable Development, 2000 examined that the online learning has associated with the cyber learning, virtual learning, online education and integrated systematic education. Kearsly, 2000 described the important themes which shapes the E-education including authenticity, centralized information, shared 
information, student-centeredness, collaboration, connectivity, unboundedness, exploration, society \& multisensory experience. Volery, 2000 also examined the online delivery of learning that is facilitated by the internet. Furthermore, Paulsen, 2002 studied that online learning has categorized by advanced learning institutions who have provided online degree as well as educational courses with the help of customary online classroom training. Allen \& Seaman's, 2003 assessed on virtual education system in U.S as statistics showed that the $80 \%$ higher schooling institutions have implemented online content delivery system. Thus, in U.S, there are widespread usage of virtual education

Virtual teaching can easily be formed as per the review examined by the U.S. Department of Education, it is suggested that 1.6 million students had been registered by offering over 54,000 virtual education courses in 1998 (Lewis et al., 1999). Allen \& Seaman, 2003 has shown the statistics: (i) those institutions who offered online courses to their students, $13 \%$ of their students had registered at least one virtual course because of institutions have the capability of providing virtual courses; (ii) over $1 / 3$ of students $(578,000)$ studied all their online courses; (iii) over 1.6 million students enrolled for virtual course in Fall semester of 2002; (iv) In U.S institutions, in Fall semester of 2002, 11\% students had registered at least one E-learning course.

\section{REVIEW OF LITERATURE}

The extra the focal point is on growing college students who can develop the operative results to actualglobal issues, the greater a success those college students' turns into. However, Crocket, 2012 stated that the 'Global Digital Citizen Foundation' works through the concept of 'Solution Fluency', which fixed issues and complications efficiently in carefully-designed answers of virtual learning.

Hetherington, 2011 pointed out the replacement of outdated course content, in 2010, for an assessment of enterprise in New South Wales. It was observed that the PBL path had an effective influence on pre-provider instructors' inspiration to demonstrate medical ideas on actual world environment.

In hassle-based studying, students study an 'investigative approach' and are searching for understanding and answers with the help of questioning as well as research of places, objects, humans, books, information and evidences. As a result, a studying method can help to search out an answer or placing a question that is carefully decided on by instructors as well as a group of students. The hassle is decided to be the area to begin for the gaining knowledge of manner, which motivates university students to keep investigating so they may be able to recognize the procedure of the problem and its' solution.

Moreover, Newbie and Clarke, 1986 inspected the hassle-based study about getting to know component in his study. A sizeable quantity of confirmation facilitates the fee of cooperative as well as active getting to know. An instructional E-lecture room environment has been described as potential factor, offers to perform synchronous as well as asynchronous virtual leaning, whilst problem based gaining knowledge of (PBL) is a technique which is used to put in force the planned situations, which includes case studies. Bignell \& Parson, 2010 studied about the beneficial useful resource in multiabilities as well as multi-disciplinary context. Although clean proof, there is a continuing discussion regarding the asynchronous usefulness instead of synchronous virtual-learning. Basically, asynchronous getting to know may have been taken into consideration an orthodox practice of e-getting to know in 2016, while students use discussion boards as well as an e-mail as the medium of conversation. This is why, the truth era has 'moved on' with the arrival of $3 \mathrm{G} / 4 \mathrm{G}$ and smartphones necessities that have made synchronous mastering \& communique not unusual in Thailand (Hrastinski, 2008).

Discussion forums are being modified with interactive as well as real-time gaining learning management systems (LMS) including schoolboy, social networking tools as well as Moodle (Modular Object-Oriented Dynamic Learning Environment) collectively with Line. While differences in technologies, social network sites (which include Line, Whatsapp) are 'web-based offerings which permit people to (1) construct a public profile as well as semi-public inside a restricted structure, (2) communicate a listing of exclusive customers with whom they percentage an association, (3) traverse view for listing of an association as well as those ended by others inside machine (Boyd \& Ellison, 2008). 
However, in innovation skills, social generation \& analyzing are essential. Learners want to be searching for self-education and development to enhance their talents. This 'mastering by using the usage of doing' technique prepares rookies for their careers which is beneficial for their future (Sun \& Kang, 2015). The talent contains the 4Cs: Collaboration, Communication, and Creativity \& Critical Thinking.

The Thailand National Education Act of B.E. 2542 (1999) requires that learning must be targeted on all components (Phungsuk et al., 2017) for the improvement of children, inclusive of records, morality, and studying strategies to increase self-learning capabilities in society. Section 66 of the act said that Thai national insurance is for university youngsters to extend their competencies for deployment of academic generation. Such deployment can offer enough expertise \& competencies in the use of technology for the attainment of information on a persistent $\&$ lifetime basis.

From an overview of researches $\&$ articles relating to hassle-based totally studying, it has been determined that the analyzing version enhances the studying effects of college students. Moreover, it encourages self-observation by the of manner of the usage of problems to inspire information in addition to discovery, which allows first-rate and greener paintings to be produced in LMS.

As formerly mounted, VLEs also may be known as LMSs includes technologically rooted apparatus which is frequently stated as the 'Web'. On the other hand, the 'Web' isn't always similar to the internet, despite the fact that the phrases are wrongly used against each other. Further, the 'Web' described as software program that runs on the mechanism called the 'Internet'. 'Web software's' have numerous types including the learning use, commonplace software/platform names, along with WordPress, Edmodo, Schoolboy, Moodle, \& Google Apps for Education are used regularly. A VLE utility get famous in 'Google Apps for Education' as Kannarik, 2014 described that it 'will provide help to different university students to get maximum beneficiary thriving success in a digital world, at the same time they're college students. Pumahapinyo and Suwannatthachote, 2014 analyzed the elements which effect the revolutionary-choice method for web-based learning system adoption for college degree software program, also it has been shown the 9 elements for implementation of e-mastering packages, collectively with: 1)public individuals of the family, 2) path best, 3) learning assist that specialize in technical workforce, 4) era support, 5) ease of use, 6) potential for self-directed studying, 7) reliability of dimension and assessment 8) learner resource that specialize in learning fabric and media, and 9) direction flexibility. Researchers additionally discussed the interconnecting nature of terminologies such as; virtual education, grouped virtual education as well as digital getting to know environments (VLE)' as 'getting to know structures' (Pumahapinyo \& Suwannatthachote, 2014).

Furthermore, O'Donnell (2012) found that University/College students have positive views regarding the modifications delivered to better schooling and specially noted VLE with the aid of using era. From above mentioned studies \& students' responses, it is concluded that the utilization of technology in higher education is beneficial for studying.

Use of era depended on the techniques which are hired professorially through an educator. The research evaluate different articles associated with the VLE decided that the students have already possessed statistics generation \& verbal exchange talents, that means they get influenced by the usage of social media efficiently. VLE fosters as well as replaces way of life mastering. Education, in modern times, is predicated on university college students being able to use on-line learning programs correctly.

Various quantitative researches (Hara \& Kling, 1999; Goodwin, 1993; Bennett \& Bennett, 2002) inspected the efficiency as well as the effectiveness of virtual mastering. On the other hand, there is lack of research about pupil factors which might give some answers related to the questions which incorporates: How do participants' capabilities have an effect on perceptions of online learning? Do students' computer abilities have an effect on virtual learning? How the conversation within virtual environment have emotional impact on scholars believes? However, Thurmond, Wambach, Connors \& Frey (2002) pointed out some questions which might be frequently disregarded or beneath inspected in research that has measured the brilliance of virtual learning.

Another vital characteristic of e-learning is the format of virtual surroundings. Clark, 2002 found that success of e-gaining knowledge depends on the designed Content. He additionally cautioned about the 
content material that e-courses need to be greater "significant, wonderful, exquisite, Planned and private" to boom university learners' retention.

Various qualitative researches (Hara \& Kling, 1999; Goodwin, 1993 and Bennett \& Bennett, 2002) had been showed on the way to know the efficiency of online mastering. On the other hand, there are insufficient studies for student factors which would give answers to the relevant questions: How do Students computer abilities have impact on perceptions of virtual first-class? How the verbal exchange inside the virtual surroundings have an effect on pupil's notion as well as Learning productivity? Moreover, Thurmond, et al., 2002 suggested some questions which are regularly omitted in studies which have measured the satisfactory level of virtual learning.

Numerous groups proposed and posted their recommendations and concepts to make certain the excellence of virtual schooling. In 2000, IHEP examined the present concepts or guidelines and suggested 24 standards for measuring first-rate web-based learning, which were divided into 7 classes: (1) mastering/ teaching, (2) school assist, (3) guide for institutions, (4) assessment \& evaluation (5) Pupil help, (6) route improvement, \& (7) path structure (IHEP, 2000). Amid the 7 classes, 3 classes are associated with students. They are course structure, student aid and teaching/mastering. The IHEP Student Benchmark scales are adopted for hypothetical background for further examining about students' perceived first-class of virtual education is compatible with IHEP Benchmarks. Students' perceived strengths of online getting to know Further Howland \& Moore, 2002 studied that the conversation among college students \& teachers was an essential difficulty. The nonappearance of participants' face-to-face interaction among teachers \& students was unpleasant for several students.

In online learning sessions, student mostly felt doubted and unconfident when the instructor delayed in guiding and giving feedback about understanding the course. Furthermore, in Howland \& Moore's, 2002, reported that students have hardly understood assignments just because of conversational loss between teachers and students. Petride's, 2002 look at on beginners' views on internet-based knowledge and mentioned that in structured face to face interaction, dialogue has immediate response, whereas in virtual education context some students face the difficulty of lacking in immediate correspondence. Mostly the fatigue and exhausted feeling arises specifically seeming in asynchronous virtual discussions, it happens to the students when they have to wait at lengthy line of time in order to get messages, or to reply and read by scrolling up \& down postings and E-mail messages. A qualitative research conducted by Hara and Kling, 1999 suggested that in online education, participants felt irritated as well as unsatisfied just because of lacking an instantaneous response from the teachers during the virtual education sessions.

Furthermore, instructor plays a vital role in the productivity of delivering an online lecture. It is not all about the technology but the accurate execution of the technology that determines the learning outcome (Collis, 1995). For instance, Webster and hackley, 1997 recommended that three instructor characteristics have impact on learning consequences: attitude with regard to technology, teaching style and command on the technology. Students are most likely to undergo the positive learning outcomes while attending a class with an instructor who has an optimistic attitude towards promoting a technology and willing to teach in distributed learning style. Moreover, students might feel isolated in a distributed learning environment as they do not have the lecture room environment in which they connect and communicate with the instructor (Serwatka, 1999). To conquer this feeling, instructors are advised to provide counselling hour and approaches of contacts for the students. Most necessarily, the instructor should focus on encouraging interaction between the students and with the instructor and promote interactive teaching style. Students in virtual learning system often face technical issues. It is important that the facilitator has a good command on technology and is capable to fix basic troubleshooting tasks (e.g. to add students at the last minute, changing the course settings). Haynes et al., 1997 commented that these basic skills and overall coordination with students are required for an instructor, as the development and enhancement of an online course is intensive, both faculty and technical resources must be recognized and dedicated to the schedule at an early stage.

There are several factors which effect college undergraduates' virtual mastering experiences. Song et al., 2004 inspected 76 college students' perceptions related to the challenging and beneficial 
aspects in virtual learning, they mentioned the difficulty in know-how academic desires, loss of community and technical troubles as challenges of their online getting to know studies. Some different elements analyzed by different scholars are learner characteristics (Howland \& Moore, 2002) as well as design of the virtual studying surroundings (Clark, 2002; Song et al., 2004). Learner characteristics encouraged academic students' experiences. Similarly, it also encouraged the virtual beginner's research and their online gaining knowledge of stories.

Besides this, technological development and students interest in online classes (Bennett and Lockyer, 2004; Britt, 2006) have created an impact on colleges and universities to carry out online classes along with the normal course. Here the most important point is online classes are to be considered as a modern technique for controlling issues during the learning process (Agustina \& Cahyono, 2017).

In addition to this, mostly universities are making arrangements to invest in internet-based virtual learning system classes and on hiring and to provide training to faculty to teach online (Floyd, 2003; Koehler et al., 2004). Some surveys suggest that online teaching system will continue to expand prominently in educational as well as the in the corporate organization in upcoming years (Meyen et al., 2002). As a result of all these advancements in education sector, it is understandable that online-based teaching is interactive (Johnston et al., 2005) and virtual teaching system produce environment where students have the opportunity to thoughtfully engage with the course material and to gain knowledge by practical activity (Palloff and Pratt, 2013). However, previously, online classes are attaining so much significance all over the world, and it transforms the thought of colleges that "Online class is an Optional" to "Online class is necessary" (Larreamendy-Joems and Leinhardt, 2006).

In modern-day on-line training practices, the textual content is the number one approach of communication. Text is observed in traditional paper based format, multi-media and on-line mediums. These texts exist inside a specific context. However, the extent of effectiveness of textural verbal exchange is more advantageous whilst included with visuals analogies, feedback and questions. Images can deliver more meaningful aspects of courses as compared to phrases. Additionally, Clark, 2002 indicated that "an image really is worth a Thousand phrases and the on-line surroundings can take gain of the capability to consist of animation, pictures, videos and different photos". Dwyer's, 2003 suggested that visualizations are powerful in line with the sort of graphical visualizations and the sort of mastering some visible aids and objective are incredibly effective in achieving particular virtual learning targets. When environment is numerous instead of textual content and verbal exchange only, college students feel pleased and happy with their studying. Thurmond et al., 2002 observed that 120 college students were satisfied with internet-based virtual learning.

Additionally, emotions are one of the factor that needs to be considered in educational research and are recognized as an essential part of student's learning (Linnenbrink-Garcia \& Pekrun, 2011; Pekrun, Stephens, Harris, \& Graham, 2012; Seligman \& Csikszentmihalyi, 2000). This is the reason why it is not considered as incidental phenomena, but an important factor in education learning process (Pekrun et al., 2012; Seligman \& Csikszentmihalyi, 2000). Furthermore, motivation, attention and self-regulation are considered the influencing factors that affects student's emotions in learning and achievements (Pekrun, Goetz, Titz, \& Perry, 2002). There are positive and negative emotions that are indulged in the learning process (Pekrun et al., 2012). Similarly, in a physical environment, virtual learning also affects the students' emotions in terms of interactions and these interactions are very important for the learning process (Keltner \& Kring, 1998).

Virtual environment emphasized on digital gaining knowledge such as computer meetings, inclusive of emails, online discussions as well as chat groups has a superior effect on pupil pleasure as compared to scholar traits. Song et al.'s (2004) study have also emphasized on the layout of virtual course. Layout is basically very supportive part in virtual learning system. However, other useful factors includes; comfort with virtual automated technologies, learner motivation as well as time management.

Digitalization has been rapidly increased in education due to which interactions have been diversified. There are new ways of learning which provides collaborative, adaptive and situated learning that increases the control, openness and choice of students over the learning process (Järvenoja \& Järvelä, 2005). Due to technological integration since year 2000, virtual learning has been included in higher 
education (Bayraktar, 2000; Christmann \& Badgett, 2000; Hsu, 2003; Larwin \& Larwin, 2011; Merchant, Goetz, Cifuentes, Keeney-Kennicutt, \& Davis, 2014; Michko, 2007; Schenker, 2007; Schmid et al., 2014; Sitzmann, 2011; Sosa, Berger, Shaw, \& Mary, 2011; Tekbiyik \& Akdeniz, 2010; Timmerman \& Kruepke, 2006; Vogel et al., 2006).

\section{Quality guarantee pointers and ideas}

The superior of virtual learning has stimulated the eyes of advanced training authorized associations. Several companies suggested \& published their principles to make sure the excellence of virtual schooling. In the start of 1990, the Western Cooperative for Educational Telecommunications (WECT) established "Principles of Good Practice for Electronically Offered Academic Degree and Certificate Programs" (Twigg, 2001). Subsequently, numerous agencies have advanced comparable practices \& concepts. For instance, the American Distance Education Consortium (ADEC) stated "ADEC Guiding Principles for Distance Learning". A mutual collaboration of the American Council of Education and their Alliance: An Association for Alternative Programs for Adults established "Controlling Values for Distance Education in a Learning Society." The Instructional Telecommunications Council has given "Quality Enhancing Practices in Distance Education." The American Federation of Teachers (AFT) stated "Distance Education: Guidelines for Good Practice." The Council of Regional Accrediting Commissions updated and defined WECT's assertion, \& posted "Guidelines for the Evaluation of Electronically Offered Degree and Certificate Programs" (Twigg, 2001)

\section{PROBLEM STATEMENT}

Online learning is an education that could be provide to any student with the help of Internet which means each and every student can get knowledge without any restriction of place, time constrained as well as free access to education. E-learning is a modern technique that helps students to get education who can't afford the education with the traditional education system. Further, the recent research has showed that the $80 \&$ online course content is delivered through online sources offered by higher learning institutions (Allen \& Seaman, 2003). Although, there have numerous benefits of online learning, but some of students still feel unwilling to get the online courses as they criticize online scheduled classes. Moreover, one student notified that "the online courses have much higher cost, and he feel like he lost all the time when he attended the online courses" (Personal communication, 2003). However, other students specified that "the online classes have bored him as he cannot feel the attachment with teacher" (Personal communication, 2003).

As the above study showed some bad experiences of participants about getting E-learning education experiences. Some negative perceptions came into surface, such as why online courses become the reason of negative experience? Was there a fault of learners? Was it a design fault in online course programs? Was it a teacher fault for not delivering course content to students in a right way? How the quality of online education courses can be measured by institutions? Are the students dissatisfied or satisfied with online education based on participants learning perceptions? What are the elements which helps students' regarding positive virtual learning perception as well as their experiences? All of above questions stimulated the current research investigation to examined students' experiences and their opinions towards getting virtual education.

\section{RESEARCH QUESTIONS}

1. What is the involvement level of students regarding virtual teaching? What they observe from the about virtual teaching from their experiences?

2. What are the matters that have shaped students' virtual teaching practice? What are those elements subsidizing the effectiveness of virtual teaching?

\section{METHODOLOGY}

In this analysis, researcher uses phenomenology by the views of participants because it examined the experiences of students about online education. The researcher collected the data by using structured 
interviews (Close ended questionnaire) supported by relevant secondary literature. For inferring the concepts, open coding, axial coding's well as selective coding of narrative data was done. Propositions were based on relationship between and among categories. After the first relational closeness, that is, categories saturation, the iterative process of collecting data was initiated till the saturation of categories. The data was collected from University students.

The analysis of memos prepared during the data collection and data interpretation finally lead to substantive and formal theory. Similarly, techniques which is used for Qualitative study consisted of; interview, document analysis as well as observations and triangulation-placing together of numerous forms \& pieces of information -which can provide helping hand for better interpretation \& analysis of a situation. Interviews has two parts in this whole process. Researcher have taken interview from four respondents by using purposive sampling.

This study has applied Phenomenology to analyze the experiences of students who are taking online classes to understand the influence of online learning on students.

\section{Data collection and analysis}

Data has been collected from private university students. And all interviews are conducted online via cell phone.

Data has been analyzed through manual coding using thematic analysis selective coding, axial coding as well as open coding.

\section{RESULTS/FINDINGS}

\section{Respondent 1}

Interviewer: As a student, how does your experience of online educational programs compare with traditional in -class instruction? How do you like or dislike it?

Interviewee: I like it because of no travelling and stress to reach the university on time. You are bit relax because no one is present to monitor or regulate yourself as it happens in traditional class environment.

Interviewer: In what ways could online education programs serve your educational needs?

Interviewee: It can fulfill the need to some extend that curriculum can be covered but the teacher and the students both are not familiar and comfortable with online classes so both can't play their part as they do in traditional classroom environment.

Interviewer: As a student, how do you feel about the communication between yourself and the instructor? Between you and other students?

Interviewee: Its bit difficult to communicate with teacher and other class mates because technical limitations are there. In class environment, there is a protocol to communicate and everybody is familiar with it but in online, nobody knows the protocol and poor internet quality disrupt the communication.

Interviewer: As a student, do you think you're learning outcomes could be achieved through online education? Why? How?

Interviewee: I am not agreed with this online culture and strongly believe that our learning objectives can't be achieved. Reason is we, from class 1 to yet, have studied in traditional class room environment and our teachers too. Therefore, both are not comfortable in this online learning system.

\section{Respondent 2}

Interviewer: As a student, how does your experience of online educational programs compare with traditional in -class instruction? How do you like or dislike it?

Interviewee: As per my experience so far, it's a great experience. I found it time saving, more organized, but I believe it's only good for highly matured and professional class students. I believe it will not work well for less matured students due to lack of interest.

Interviewer: In what ways could educational programs serve your educational needs? 
Interviewee: It is time saving and cost of fuel saving.

Interviewer: As a student, how do you feel about the communication between yourself and the instructor? Between you and other students?

Interviewee: I am satisfied with both, but yes may be because we had few physical classes, so because we already know each other and have a sense of connectivity, we get comfortable in online classes too. I believe at least few interactions with instructor and class mates are important for connectivity.

Interviewer: As a student, do you think you're learning outcomes could be achieved through online education? Why? How?

Interviewee: If you are talking about transformation of complete education from physical to online, I believe it's not only the classes, you learn a lot from meeting, interacting and observing others. And within institute, disciplinary rules have a lot of impact on your personality so I am in favor of at campus classes more than online learning.

\section{Respondent 3}

Interviewer: As a student, how does your experience of online educational programs compare with traditional in -class instruction? How do you like or dislike it?

Interviewee: It is really the need of the time as universities have started online classes. However, I have also been a part of this exercise and I have conducted classes as well as taken classes and I have come to a conclusion that online education in beginning seems to have some hurdles, some setbacks and it has certain issues. It has some communication barriers which with passing time could be resolved. I myself disliked online classes at start because of its limitations and lack of human interaction However, in these times, where the Covid-19 pandemic has become a challenge for the whole world, this is a logical choice that we need to conduct online classes.

Interviewer: In what ways could educational programs serve your educational needs?

Interviewee: I think to replicate a classroom setting seen, what we need to do is that we need a certain type of software which could resolve low data connectivity issues. If it is resolved and the teachers also have a receptive attitude towards questions of students, and students also play a part by not asking irrelevant questions during the class, these online sessions could become beneficial for both the teachers as well as the students.

Interviewer: As a student, how do you feel about the communication between yourself and the instructor? Between you and other students?

Interviewee: Yes. This is something very important because it talks about your relationship with student, with your course instructor. There are certain things we want to communicate with our colleagues or course students. So this is the case then the course instructor should clearly mention that if any student wants to have a private discussion online with the teacher, that facility should be available too. Since a lot of people are there in the online class, all of the students do not get a chance to speak. So, there should be improved communication between the teacher and the students. The students should not ignorant of the fact that he/she cannot ask personal question. It could be asked even in the online class. Interviewer: As a student, do you think you're learning outcomes could be achieved through online education? Why? How?

Interviewee: Personally, as a teacher as well as a student, I do not feel that it we will be achieving our learning outcomes that early, because none of us is accustomed to online learning. Online learning requires different set of skills so that we are able to imbibe the concepts what the teacher is trying to tell us. Secondly, I think that online education requires that the student reads and understands everything on its own and only asks question from the course instructor unlike the normal culture which prevails in Pakistani universities where the course instructor provides a full fledge lecture and a full explanation of each and every thing which is containing in the book. So, I think we need to adapt and understand to this online educations stuff to make the most out of it and to achieve our learning 
objectives, and we will be able to do this with practice and with trial and error, on trial and error basis based on our own experiences which is not something that we cannot achieve.

\section{Respondent 4}

Interviewer: As a student, how does your experience of online educational programs compare with traditional in -class instruction? How do you like or dislike it?

Interviewee: I think that experience of online education programs has some pros and cons, and cons are that you are really busy in your other routine work such as housework, house chores or office work or travelling or some other things that are going on in your life, but when you are in university campus you are more committed and you have nothing else to do as you are totally focused. So, obviously the on campus experience is way better than online class, but due to Covid-19, I think that it is a really good initiative from the educational institutions all over the world that they are pursuing the online education and this does not interrupt our schedule of the semester exams and all that.

Interviewer: In what ways could educational programs serve your educational needs?

Interviewee: Well, obviously they are just a temporary means of pursuing your education, they are not a permanent means.

Interviewer: As a student, how do you feel about the communication between yourself and the instructor? Between you and other students?

Interviewee: I think the communication between myself and instructor is no big hurdle, especially when there is a whatsapp group and the instructor is available via mobile phone communication. So, I don't think there are any hurdles in communicating between yourself and the instructor, but it also depends on the degree level as if you are a college or school student, you are not frank with the instructor. If you are at MSC or MPhil level, instructor will be more open to you and will guide you. So this depends on the level of educational that you are getting.

Interviewer: As a student, do you think you're learning outcomes could be achieved through online education? Why? How?

Interviewee: I think the learning outcomes can be achieved through online education because as I've said that you can get all the international certifications at your doorstep. So if you want to become a certified specialist or if you want to become project management professional from USA, you do not have to go to USA for that. So I think this is the biggest advantage. Even you can get MIT forces at your doorstep. Learning outcomes can be achieved but depends that you stay focused. If you cannot stay focused, then the campus classes are more suitable to/for you.

\section{Lack of useful resource and education}

In Pakistan, education centers are not prepared to facilitate students with fast internet availability and search engines like google and yahoo. Secondly, college students are not provided with login ids to work at home or on weekends. They can use college resources only from within university. Another reason is lack of proper schooling of researchers. It often takes place that at the time of their defense, researchers discovered deficient in vital factors / pillars of research. Many students may not realize proper distinction amongst combined technique studies and qualitative research. Students are regularly ignorant about philosophy of research.

\section{Difference in problem and tactic}

Pakistani universities have hassle their very own tactics of doing research at very primary stage. They locate journals for e-book after completing research rather doing it prior research.

\section{Load of teaching and other academics sports}

University faculty have many obligation regarding coaching, e book development, supervisory, etc. They did want to do research because of load of extra responsibilities assigned by universities. 


\section{Lack of Research Skills}

The set of research capabilities are required like, critical wondering, technical abilities, Statistical and Graphical analysis of data, ability to keep manage necessities, planning and scheduling, research interviewing, and the most crucial one is analyzing and writing skills.

\section{Barriers to provide proper studies}

There are a few boundaries to offer research productivity concerning lack of data, lack of clarity, lack of proper statistics, lack of theoretical foundations or arguments, lack of knowledge techniques and absence of proper information as well.

\section{CONCLUSION}

The intensity of information obtained though the assessment of observations, archival statistics as well as interviews have supplied a degree of qualitative approach. While getting virtual education, individuals received every terrific and terrible testimonies, but the fact that their reminiscences tended to be extra immoderate tremendous. Flexibility of class contribution time, no allotment for extra time to be prepared for physical classes, provision of time to be engaged in multiple works, effectiveness of on line knowledge content, familiarity with instructor, virtual research availability, nicely-designed path format, easy online navigation interface as well as ease of internet connection contributed to students' positive reviews regarding virtual learning. Factors that contributed to student' bad reviews have been: lack of comments from teacher; feeling of isolation, lack of physical interaction, unapproachable technical useful resource from trainer, lack of good teaching, poorly-designed course content material as well monotonous academic techniques. All these components have mainly contributed to the quality of virtual education.

\section{REFERENCES}

Allen, I. E., \& Seaman, J. (2016). Online Report Card: Tracking Online Education in the United States. Allen, I.E., \& Seaman, J. (2013). Changing course: Ten years of tracking online education in the United Allen, I.E., \& Seaman, J. (2014). Grade change: Tracking online education in the United States. Babson Anderson, B., \& Simpson, M. (2007). Ethical issues in online education. Open Learning: The Journal of anytime. Journal of Engineering Education, 94(1), 131-146. Babson Survey Research Group.

Bourne, J., Harris, D., \& Mayadas, F. (2005). Online engineering education: Learning anywhere, Education with Virtual and Remote Labs. IEEE Global Engineering Education Conference (EDUCON) (pp. 1136-1139).

engagement" and "cognitive presence" in online education. Computers \& Education, 52(3), 543553.

Harasim, L. (2000). Shift happens: Online education as a new paradigm in learning. The Internet and higher education, 3(1), 41-61. Open, Distance and E-Learning, 22(2), 129-138.

Perales, M., Pedraza, L., \& Moreno-Ger, P. (2019). Work-In-Progress: Improving Online Higher programs. Online Journal of Distance Learning Administration, 4(1), 1-11.

Shea, P., \& Bidjerano, T. (2009). Community of inquiry as a theoretical framework to foster "epistemic

Shelton, K. (2011). A review of paradigms for evaluating the quality of online education States. Sloan Consortium. Survey Research Group.

Volery, T., \& Lord, D. (2000). Critical success factors in online education. International journal of educational management. 
A Phenomenological Exploration of Virtual Learners' Experiences 